\title{
Intelligence And Diversity: A Western And Eastern View From A Global Paradigm
}

Stefanie Denise Wilson, University of Hawaii-West Oahu Bahaudin G. Mujtaba, Nova Southeastern University

\begin{abstract}
Intelligence, whether hereditary or acquired, has been the subject of discussion since the beginning of time. Multiple intelligences have been in existence for thousands of years and the use of these various capabilities can greatly impact a person's thinking, feelings, and habits. Based upon previous studies and experiences on multiple intelligences, this paper attempts to shed light on the topic from a global perspective to clarify the stereotypes regarding intelligence which are attached to people of different countries, cultures, and genders. Research has identified a relationship between the domains of multiple intelligences such as interpersonal, intrapersonal, linguistic intelligences, leadership, and demographic characteristics such as, age, gender and ethnicity among various populations and professions. Using literature and secondary sources, the authors provide a view of multiple intelligences from a global perspective along with a theoretical framework. Studies seem to indicate that despite the existing stereotypes people of all backgrounds and cultures have similar levels of intelligences. The paper concludes by offering a discussion on the skills of social intelligence as well as suggestions on respecting and understanding each other's differences. The literature and content can be useful for clarifying stereotypes, management selection, as well as training and development in today's global corporations that are competing in a highly complex world.
\end{abstract}

\section{INTRODUCTION}

C n the 1860s, Broca demonstrated a correlation between specific cognitive impairments and specific brain lesions. Then Galton developed a statistical method to rank the physical and intellectual powers and correlated them with one another, verifying a link between biology and professional accomplishment (Gardner, 1983). For centuries, research has been conducted in an attempt to distinguish individuals who are intelligent from those who are less intelligent (Valencia \& Suzuki, 2001). Since the emergence of the psychological testing movement launched in Europe and credited to Galton, and the development of cognitively based intelligence testing by U.S. psychologists Binet and Simon in 1905, has emerged contemporary research on intelligence extending beyond the conventional intelligence quotient (IQ) measures (Lussier \& Achua, 2001). There are a variety of paradigms in the field of human intelligence, where there are as many inquiries as there are answers on this topic (Sternberg \& Kaufman, 1998). Sternberg and Kaufman state that "These paradigms are largely complimentary rather than contradictory, looking at different aspects of and questions about intelligence" (1998, p. 497).

Regardless of one's level of intelligence, people are likely to be victims of cultural conditioning, stereotypes and biased paradigms that exist in one's surroundings. As intelligent professionals who are aware of people's differences, we do need to avoid biased and sexist thinking and language in our vocabulary in the workplace. As a matter-of-fact, this continuous thinking can help us eliminate biases and stereotypes from our heads, hearts and eventually our habits. The recently published book entitled "Workforce Diversity Management: Challenges, Competencies and Strategies" (2007), offers examples of stereotypes and biases during our socialization process in society and how human beings are often acculturated to continue acting based on past conditioning until they formally replace the "automatic pilot" mentality with conscious thinking based on facts. This is why it is important to think differently using our heads (cognitive abilities and intelligences), feel differently through our hearts, and act differently thereby changing our daily habits. It all starts by thinking and acting in a bias-free manner. 
The suggestions, stated throughout the Workforce Diversity Management" book, offer diversity management ideas so professionals can be successful in achieving their stated outcomes synergistically. Many of the suggestions have been used by the authors as well as trainers, managers, educators, and leaders throughout the world to create a productive and happy work environment for all. As stated by Mahatma Gandhi, "Happiness is when what you think, what you say, and what you do are in harmony.

The "Workforce Diversity Management book is about creating harmony in one's head (thoughts), heart (feelings), and habits (behaviors) about people of diverse backgrounds and cultures. It is fair to say that diversity and culture-related issues are likely to, and should, impact a person's head, heart and habits if they are to lead to long-term peace and prosperity in life. The Workforce Diversity Management book offers practical thoughts regarding the head, heart and habits concept (Mujtaba, 2007). Head implies continuous cognitive learning about each situation, thinking objectively based on current facts, awareness of universal principles, and knowledge generation. Heart implies the consistent controlling of one's feeling, basing it on objective facts, and aligning it with universal values. It means basing one's feeling for long-term impact, rather than short term satisfaction of personal desires that are linked to revenge, vengeance, payback, or retribution. Habits should be linked to one's objective feelings and universal principles. It means ensuring that one's day-to-day behaviors are aligned with one's universal principles of right and wrong, personal or professional values, and knowledge-based and goal-oriented feelings. Of course, the effective application of one's head, heart and habits require planning and the effective use of multiple intelligences which are within all human beings. Let us start by understanding what intelligence is and how it is acquired.

\section{WHAT IS INTELLIGENCE?}

What intelligence is has been a topic of inquiry for centuries. There are many definitions of intelligence with little similarity, based on who you ask, across disciplines, times, and places (Miele, 2002; Sternberg \& Kaufman, 1998). Some experts believe intelligence is "the importance of the ability to learn and the ability to adapt to the environment, while others, emphasize metacognition, or the ability to understand and control oneself" (Sternberg \& Kaufman, p. 481). While the nomenclature of metacognition is new, Aristotle and Plato emphasized the significance for intelligence of knowing oneself, and advocated an intellectual life centuries ago (Moore \& Bruder, 2002; Sternberg \& Kaufman).

Earley and Ang (2003) stated that while researchers and theoreticians contend that intelligence is not easily definable; there is a consensus on the attributes of intelligence, which are as follows:

1. At the biological level of analysis, an intelligent person must have control and regulation over elementary sensory organs including perception, sensation, and attention.

2. At the mental functioning level, intelligence represents higher-level components of cognitive functioning, such as cognitive processes of representation, abstract reasoning, problem solving, and decision-making.

3. Within the realm of mental functioning, intelligence must also embrace metacognition and executive processes. Thus, a person is intelligent not only in what he or she knows, but in his or her ability to know how to know.

4. An intelligent individual must possess some form of crystallized, formal, learned declarative, and/or experiential procedural knowledge in a domain or domains.

5. In terms of behavioral manifestation of intelligence, intelligence must be defined in some overt form of behavior, either verbal or non-verbal, because one of the core definitions of intelligence is the ability to adapt to one's surroundings as well as to new stimuli or environments.

6. The content of intelligence is culturally bound, that is, intelligence is an attribute of an individual operating within the culture of an environment that defines what intelligent behavior is. (p. 29).

Researchers and theoreticians have defined culture and cultural intelligence in numerous ways. Harris and Moran (1996) offered a useful definition by suggesting, that "culture is a distinctly human capacity for adapting to circumstances and transmitting this coping skill and knowledge to subsequent generations" (p. 10). Earley and Ang (2003) had an interesting perspective on cultural intelligence. Early and Ang (2003) argued that "cultural intelligence refers to a person's capability to adapt effectively to new cultural contexts" (p. 59). Other theorists have 
expressed a socialization process that is an integral aspect of culture and cultural intelligence. "Different socialization practices [have emphasized] the development of modes of knowing that have relevance and value in a particular cultural context" (Riggio et al., p. 189). Thus, there are diverse views regarding what intelligence is globally across cultures. "Given these differences it is possible to be considered highly intelligent in one culture and intellectually lacking in another, based on the same skills or behaviors exhibited" (Riggio et al., 2002, p. 190).

Research findings indicated that differences between cultures in conceptions of intelligence reflect the various cultural groups' emphases on aspects of intelligence most valued (Valencia \& Suzuki, 2001). The difference may be attributed to the kinds of philosophies deeply rooted in each culture. The practices developed in one culture, society, or environment may not be considered intelligent or easily transferred to another culture, society, or environment (Earley \& Ang, 2003; Harris \& Moran, 1996). Not only may variations exist between cultures, within cultures, transmission of cultural meanings within a society may also be imperfect (Earley \& Ang). "Any two individuals from a common culture may hold slightly different meanings for the same event or construct, and these two individuals may have shared meanings with other parties in the society but not one another" (Earley \& Ang, p. 63). Since cultural differences may vary in skills and the ideal combination of cognitive processes within or between cultures, it is reasonable to expect that people from similar or different backgrounds may also differ in their problem solving approaches and in the patterns of skills acquired.

\section{Western View Of Intelligence}

The Western emphasis of intelligence focuses on verbal abilities and speed of mental processing, a view not necessarily shared by other cultures (Sternberg, 2003; Valencia \& Suzuki, 2001). However, many prominent Western theorists do not support the notion that intelligence is based solely on verbal abilities and speed of mental processing (Sternberg \& Kaufman, 1998). Some widely-known Western theorists have addressed the significance of the depth of processing in lieu of speed for full command of material.

While the Western view on intelligence varies, one of the beliefs shared by Western theorists is that an intelligent person places an emphasis on "learning." The Western view of "the intelligent person is one who spends much effort in learning, enjoys learning, and persists in life-long learning with enthusiasm" (Sternberg \& Kaufman, 1998, p. 481). Technological intelligence is also highly emphasized by the Western cultures and has significance in their school curriculums. Thus, due to the heightened importance of technology, in some cases the development of tangible objects such as artificial intelligence and smart bombs are viewed as technological intelligent, or smart (Mundy-Castel, 1974). A longstanding debate among Western theorists is the essence and accuracy of what intelligence tests measure. Riggio et al., [as cited in Miller, 1997] stated, "traditional Western intelligence tests may measure well the values of Western society such as academic achievement and analytical thinking processes, but provide poor measurement of the forms of knowing that are adaptive and valued in other types of societies" (2002, $p$. 190).

\section{Eastern View Of Intelligence}

Yang and Sternberg's (1997) researched study findings on the views of Chinese philosophical conceptions of intelligence were rather interesting. In contrast to the Western perspective, "the Taoist tradition emphasizes the importance of humility, freedom from conventional standards of judgment, and full knowledge of oneself and of external conditions" (Sternberg, 2003). A study conducted by Chen and Chen of Chi li [as cited by Valencia \& Suzuki, 2001] with first year undergraduate college students attending Hong Kong universities found that student's believed the most highly valued skill for measuring intelligence was nonverbal reasoning; it was rated as significantly more relevant than verbal reasoning or social skills which came next as highly valued skills for measuring intelligence, followed by numerical skills. Yang and Sternberg also found that "Confucian perspectives largely emphasize the characteristics of benevolence and of doing what is right” (Sternberg, 2003, p. 7).

Yang and Sternberg (1997) studied modern Taiwanese Chinese ideas of intelligence and the findings were different from the Taoist or the Hong Kong student's views (Sternberg \& Kaufman, 1998). "Yang and Sternberg found five factors underlying these conceptions of intelligence; (a) general cognition factor, much like the general 
intelligence factor in conventional Western tests; (b) interpersonal intelligence; (c) intrapersonal intelligence; (d) intellectual self-assertion; and (e) intellectual self-effacement" (Sternberg \& Kaufman, 1998, p. 481). It is believed that the variation of findings resulting from the Chinese research studies are primarily attributed to the subpopulation differences, methodology variations, and the timing of the studies conducted (Sternberg, 2003).

Das [as cited in Sternberg \& Kaufman, 1998] studied Eastern notions of intelligence and "suggested that in Buddhist and Hindu philosophies, intelligence involves waking up, noticing, recognizing, understanding, and comprehending" (p. 482). There were other intellectual elements considered important in Buddhist and Hindu philosophies as well. For example, more intellectual elements include "such things as determination, mental effort, and even feelings and opinions" (Sternberg \& Kaufman, p. 482).

Gill and Keats [as cited in Valencia \& Suzuki, 2001] "conducted comparative researches on Malay and Australian psychology students, differences in the definition of intelligence were found" (p. 42). The study revealed that Australian university students held in high regard academic acumen and the capacity to adapt to new situations as vital aspects of intelligence, whereas Malay students place emphasis on adaptability, speed, and creativity of problem solving (Sternberg, 2003). This study also indicated that Malay students stress both social and cognitive characteristics as important aspects of intelligence (Sternberg, 2003; Sternberg \& Kaufman, 1998; Valencia \& Suzuki, 2001).

\section{African View Of Intelligence}

Studies conducted in Africa provide another view of intelligence. In contrast to the Western view of silence regarded as an individual conveying a lack of intellect, the Wolof tribe of Africa considers those who speak less are of higher social class and distinction (Sternberg, 2003, Irvine, 1978). Ruzgis and Grigorenko [as cited in Sternberg \& Kaufman, 1998] argued that "in Africa conceptions of intelligence revolve largely around skills that help to facilitate and maintain harmonious and stable intergroup relations; intragroup relations are probably equally important and at times more important" (p. 482). Studies of the African view of intelligence not only reveal an emphasis on intergroup and intragroup relations, as other qualities are deemed important as well. Super and Harkness [as cited in Sternberg \& Kaufman, 1998] described Serpell's study which revealed, "Chewa adults in Zambia emphasize social responsibilities, cooperativeness, and obedience as important to intelligence; intelligent children are expected to be respectful of adults. Kenyan parents also emphasize responsible participation in family and social life as important aspects of intelligence" (p. 483). In Zimbabwe, 'ngware' is the word used to convey intelligence, as in social relationships, it is believed that one should be prudent and cautious (Sternberg \& Kaufman). Among the Baoule, "responsibility, initiative, honesty, verbal memory, speaking in a socially appropriate manner, maturity, wisdom, luck, observation, manual dexterity, and attention are seen as key to intelligence" (Valencia \& Suzuki, 2001, p. 44). Research findings on the people of Baganda offer another perspective regarding what is believed constitutes intelligence. Wober [as cited by Riggio et al., 2002] noted that, "Baganda people of Uganda associate intelligence with careful, slow, and deliberate thought. They value the careful consideration of many alternative solutions with slow internal examination before sharing thoughts with others" (p. 190). It is evident that Baganda's view of intelligence is quite different from some Western theorist's emphasis of intelligence based on processing speed.

\section{Asian View Of Intelligence}

The view on the social skills as an aspect of intelligence is not limited to African cultures, as the Asian culture shares a similar perspective (Sternberg, 2003; Sternberg \& Kaufman, 1998). The social aspect of intelligence in many Asian cultures has greater significance than conventional Western or IQ-based cultures, and their view of an intelligent person includes qualities such as task efficiency, originality, reading, and writing (Valencia \& Suzuki, 2001). Studies have indicated that although African and Asian cultures place a greater emphasis on social skills as an aspect of intelligence, more so than their conventional U.S. conceptions of intelligence, they also perceive the cognitive aspects of intelligence as significant (Sternberg \& Kaufman, 1998; Sternberg, 2003). 
In the Afghan culture, similar to their other Asian colleagues and African counterparts, intelligence is often expected and perceived from the behavioral aspects of people's demeanor. People who speak too often, too loudly, and "out of turn" are not necessarily seen as the most intelligent individuals despite the fact that they may very well be highly accomplished individuals. However, a high level of education in technical fields such as engineering, architecture, medicine, and other such professions is often linked with high intelligence. Afghans consider their elders, and those with a spiritual background that have devoted their lives to the wellbeing of people, of a higher social class and distinction than other ordinary citizens. Those who have and show respect for their elders, believe in a higher spiritual power, assist the poor and the disadvantaged, and behave to personally model the highest levels of excellence are deemed to be intelligent individuals by most people in Afghanistan.

\section{Latin View Of Intelligence}

Studies on the Latin view of intelligence were conducted by Okagaki and Sternberg. Okagaki and Sternberg [as cited in Sternberg \& Kaufman, 1998] found that "different ethnic groups in San Jose, California, had rather different conceptions of what it means to be intelligent" (p. 483). Their study findings indicated that social-competence skills were considered an important aspect of intelligence to Latin parents of school children (Sternberg, 2003). Okagaki and Sternberg's findings also support the notion that there is a rank order of performance for those children from diverse cultures (e.g. Latin and Asian cultures) that is evident when the parents shared the teacher's view of intelligence. Furthermore, "Teachers tended to reward those children who were socialized into a view of intelligence that happened to correspond with their own" (Sternberg, p. 10).

\section{Cultural Intelligence Complexity}

The complexity of intelligence has existed for decades, with an ongoing debate among theorists as to the emphasis placed on cultural, environmental, and genetic factors (Valencia \& Suzuki, 2001). "The concept of human biological races is a construction socially and historically localized to $17^{\text {th }}$ and $18^{\text {th }}$ century European thought. Over time, different cultures have developed different sets (folk taxonomies) of socially defined races" (Fish, 2002, p. 8). The behaviors that are deemed as a significant aspect of intelligence vary from one culture to another or in some instances vary within the same culture. "Given this complexity, true adaptation, true cultural intelligence means a willingness to forgo the boxes, and to treat people as unique combinations of values, preferences, and needs" (Riggio et al., 2002, p. 199).

Genetic evidence rejects the misleading notion that there are distinct evolutionary lineages within humans, and clearly indicates that humans are a single species that share the majority of their genetic variations and adaptive traits (Fish, 2002). Furthermore, genetic evidence clearly indicates that biological races simply do not exist, and the genetic differences that do exist are explained primarily by geography and local adaptations. According to Fish, "Human physical appearance varies gradually around the planet, with the most geographically distant peoples generally appearing the most different from one another" (p. 8). Our world characterized by a hybridization of cultures, splitting or separating individuals into categorical boxes based on culture of origin may be ineffective, offensive, and genetically indefensible and biologically misleading (Fish, 2002; Riggio et al., 2002). Fish suggested:

We go on to explore the details of human biological variability and intelligence. It is a long way from the assertion that the Caucasoid, Mongoloid, and Negroid races differ in innate intelligence to the rather different scientific conclusion that the human species has no races, that there is no single form of intelligence, and that formal education helps people to develop a number of cognitive abilities. (p. 27).

Perhaps the best promise of developing meaningful and positive leader-follower relations lies in understanding the modest levels of differentiation of each individual in all his or her complexity (Riggio et al., 2002). Rather than focusing on intelligence being based on ethnicity, gender or culture, it is more fruitful for leaders and researchers to study and understand the general theories of intelligence as they apply to all human beings. 


\section{THEORIES OF INTELLIGENCE}

Literature on the theories of intelligence suggests that there are two basic kinds of intelligence theories: explicit or implicit theories. Implicit theories of intelligence are based, or tested, on people's perception of what intelligence is (Sternberg, 2003). The goal of implicit research studies is to find out the form and content of people's informal theories, and the findings are typically used as a basis for developing explicit theories. Explicit theories differ from implicit theories and are based, or tested, on data collected from people conducting activities to measure intelligent performance (Sternberg). "People's everyday judgments of each other's intelligence always have been and continue to be much more strongly guided by their implicit theories of intelligence than by any explicit theories (Sternberg, p. 5). Several explicit theories, namely, cognitive theories, biological theories, and psychometric theories are discussed further.

\section{Cognitive Theories}

Cognitive or information-processing theories of intelligences attempt to understand human intelligence in terms of the mental processes or observable behavior, that is the level of knowledge, ability, or experience that links to cognitive task performance (Sternberg \& Grigorenko, 2003). Galton believed intellectual ability equated to mental processing speed and one's ability to perceptually discriminate, whereas Binet suggested that intellectual ability involved domains of specific skills and facts, and Cattell's conception of intellectual ability consistent with both Galton and Binet's views, emphasized general ability coupled with specific knowledge (Sternberg \& Grigorenko).

While many cognitive theories share a common thrust, their view regarding the level of cognitive functioning differs (Sternberg, 2003). Some theorists emphasize the sheer processing speed of information as a measure of intelligence, whereas other theorists have negated sheer processing speed as an indicator of intelligence and emphasize choice speed, meaning, the accuracy of and strategies in information processing (Sternberg, 2003).

The pure processing speed has been widely used for centuries, since the inception of the psychological testing movement credited to Galton. Sternberg (1985) stated that "based on studies conducted by researchers from the early to late 1900s, such as Wissler, Lemmon, Lunneborg and Jensen, the levels of correlation obtained between measures of simple reaction time and various standard measures of intelligence, none of which are perfect in themselves, have been rather weak. (p. 10)

Studies based on "choice reaction time tests" driven from speed in making choices or decisions based on stimuli have had higher correlation results with psychometric measures of intelligence. The higher correlation is attributed to increasing the number of choices in a choice reaction time test. Sternberg (1985) asserted, "increasing the number of choices in a choice-reaction-time task seems to increase correlation with IQ, but the task is still a long way off from providing casual accounts of individual differences in psychometrically measured IQ" (p. 11).

Over the decades there has been much progress in understanding individual differences in human cognitive ability and the impact ability, experience, and knowledge have on cognitive performance (Sternberg \& Grigorenko, 2003). However, additional research is needed to clearly articulate the dynamics of ability, experience and knowledge in relation to performance (Sternberg \& Grigorenko). "In spite of scholarly inquiry over two thousand years, and intensive empirical and theoretical effort in modern times, [cognitive ability] key aspects, knowing and reasoning, their origins, and diversity in them, remain obscure" (Richardson, 1998, p. 1). It is believed that a first step to gaining additional valuable insight regarding an understanding of cognitive performance is to ascertain a consensus on definitions and measurement criteria of ability, experience, knowledge, and cognitive performance (Sternberg \& Grigorenko).

\section{Biological Theories}

Unique insights have been gleaned from biological approaches linked to the nature of intelligence. Many theorists suggest that the base of intelligence is in the brain, and should be based on biological or scientific evidence 
about the brain and its functioning (Sternberg, 2003; Sternberg \& Grigorenko, 2003). "An important approach to studying intelligence is to understand it in terms of the functioning of the brain, in particular, and of the nervous system, in general" (Sternberg \& Kaufman, 1998, p. 485). Early biological theories were developed by Halstead, Hebb, and Luria (Sternberg \& Kaufman). "Earlier theories relating to brain intelligence tended to be global in nature, although not necessarily backed by strong empirical evidence" (Sternberg \& Kaufman, p. 485).

Halstead [as cited in Sternberg \& Kaufman, 1998] "suggested that four biological based abilities, such as integrative field factor, abstraction factor, power factor, and directional factor are primarily functions of the cortex of the frontal lobes" (p. 485). Hebb had a different theory regarding biological intelligence. "Hebb distinguished between two basic types of intelligence: Intelligence A and Intelligence B. Intelligence A is innate potential; Intelligence B is the functioning of the brain as a result of the actual development has occurred" (Sternberg \& Kaufman, p. 485). Another biologically based theory was developed by Luria, who suggested that the brain is a system whose cortical regions are accountable for varied aspects of the unified whole (Sternberg \& Kaufman; Sternberg). Luria's theory suggested that the brain has several units with respect to intelligence: "(a) a unit of arousal in the brain stem and midbrain structures; (b) a sensory-input in the temporal, parietal, and occipital lobes; and (c) an organization and planning unit in the frontal cortex" (p. 485).

Biological research regarding the nature of intelligence has surfaced a myriad of findings over the decades. One of the greatest advantages of biological research as it pertains to the nature of intelligence has been the acknowledgment that the brain is the seat of intelligence, and in recent times the ability to specifically identify areas of the brain for certain functions (Sternberg, 2003). One of the greatest disadvantages of biological research linked to intelligence has much to do with interpretation of the approach. Many theorists would like to suggest that an understanding of intelligence has only to do with an understanding of the brain. This approach is simply not the answer, as "differences in this biological intelligence can be measured by means of IQ tests, but only indirectly, and with an admixture of inputs from many environmental sources [such as] socioeconomic status, education, family upbringing, and cultural factors" (Eysenck, 1998, p. 61).

\section{SOCIAL INTELLIGENCE}

Despite the differences in acquired or hereditary intelligence, and to become culturally competent individuals, all professionals should learn the skills of social intelligence. The book entitled "Social Intelligence: the New Science of Success," written by Karl Albrecht in 2006 and summarized by Dr. Raimi Abiodun in Workforce Diversity Management book, discusses some basic tenets of human relations that should be practiced by each professional and managers in the workplace. Albrecht's (2006) goal is to help professionals, managers and leaders see the beauty in human behaviors and at the same time to let people understand those behaviors that differentiate effective leaders from ineffective ones. Effective leaders, according to Albrecht (2006), are those leaders who exhibit nurturing behaviors: behaviors that make people feel valued, capable, loved, respected, and appreciated. The book recognizes other forms of intelligence such as abstract intelligence, practical intelligence, emotional intelligence, aesthetic intelligence, and kinesthetic intelligence. Albrecht (2006) defines emotional intelligence as self-awareness and self-management, while social intelligence is defined as the way to deal with people. The idea is that one has to know the self first before one can improve the situation of others.

According to Albrecht, the global working environment of the twenty-first century has changed, as have the expected behaviors from managers and employees. Successful organizations must develop a better mechanism to recruit and retain good and knowledgeable workers from diverse backgrounds. Promoting a caring culture will depend on leaders' behaviors. The author specifically defines social intelligence (SI) as "the ability to get along well with others and to get them to cooperate with you." These abilities are the most important ingredients in our efforts to develop successful relationships. Albrecht hypothesizes several dimensions of basic interaction skills, empathy being one of them, that can be used to develop, assess, and describe social intelligence on a personal level. With regard to the dimension of empathy, the leader must be able to show people that he or she can identify with and appreciate them for who they are. It is this sense of connectedness that establishes a condition of rapport between two people and inspires followers to cooperate with their leaders. The author provides two ways for leaders to ensure that they are perceived as caring. Albrecht urges leaders to avoid or abandon toxic behaviors and increase the 
use of nourishing behaviors. Empathy, according to the author, is a long-term investment and not an episodic application of charm. Albrecht believes that leaders cannot expect followers to respect and accept their leadership if they constantly abuse, insult, and make them feel insignificant or unworthy. The road to complete acceptance, according to the author, is to get them to share a feeling of connectedness with you as a leader, making them closer, rather than farther from you.

It is a fact that inappropriate behaviors by managers and employees make employee retention difficult and makes effective relationships a difficult objective to achieve in an organization. However, effective interpersonal relationships are an important tool for quality leadership and productive organizations. Furthermore, developing a positive relationship with a diverse workforce could come from a corporate culture that institutes better corporate behaviors through education and training in the area of workforce diversity management.

\section{SUMMARY}

The literature review unequivocally supports the notion regarding the significance of effective leadership as the foundation of organizational success, and how effective leadership selection, training, and development is paramount to making organizational success a reality. Current literature also purports that learning organizations of today and tomorrow will require innovative and viable selection, training, and development approaches to attract and retain exceptionally talented and skilled individuals, be it leaders or non-leaders. It is believed that the theory of multiple intelligences is a viable answer that addresses this challenge, and offers solid approaches to enhance human intelligences, and individualized learning that will contribute to organizational success.

Studies do show that there are differences in how people of different cultures and genders see and approach various situations. However, the differences in the way men and women see, approach of prioritize things as per their paradigms might have more do with their nurture than nature or intelligences. For example, studies conducted by major researchers on moral judgments indicate that females tend to place a greater emphasis on interpersonal considerations, as males tend to draw on intelligences such as logical/mathematical thinking. Dessler writes that "Women often score higher on measures of [intrapersonal, interpersonal, and linguistic intelligence characteristics, such as] patience, relationship development, social sensitivity, and communication" (Dessler, 2001, p. 305). Perhaps the same can be said for people of various cultures and backgrounds that have been brought up with conditionings and nurturing behaviors that expect and reinforce certain aspect of intrapersonal, interpersonal and linguistic intelligences. Regardless of one's upbringing and past conditioning, it is always helpful to clarify the facts, discuss the existing stereotypes, make clear the expectations of the company in the work environment, and provide a healthy learning environment for all. It is also helpful to create culturally competent individuals for expecting all professionals to become TRUE diversity champions.

Regardless of one's level of intelligence, through effective diversity training and management, managers and professional can become TRUE cross-cultural leaders that are able to work effectively in the context of cultural differences both nationally and internationally. Becoming a "TRUE" cross-cultural professional and diversity champion initially requires:

- $\quad$ Tolerating differences,

- Respecting differences,

- Understanding differences, and

- $\quad$ Examining and exploring appropriate options.

The first step is usually the most difficult but a very important step in the process of becoming a TRUE diversity manager. For example, tolerance is a personal decision. It comes from an attitude that is learned. TRUE diversity management requires that people embrace the belief that each person on earth is a treasure who must be treated with respect. Human beings have the power to change their attitudes to overcome ignorance, and to influence their offspring, peers and colleagues positively. It begins with a personal commitment to consciously and intelligently choose one's speech and thought patterns. As an initial step, one can stop labeling individuals with oppressive terms based on first impressions, ethnicity, gender, or physical appearance. Through their consciously 
acquired and natural levels of intelligence, culturally competent individuals and TRUE diversity champions create an inclusive work environment. These champions understand that the most intelligent individuals on earth respect human diversity and provide an avenue for all individuals to reach their full potential as per their dreams and capabilities.

\section{BIBLIOGRAPHY}

1. Albrecht, Karl (2006). Social Intelligence: the New Science of Success. Jossey-Bass.

2. Armstrong, T. (1999). Seven kinds of smart. New York: Plume \& Penguin Putnam, Inc.

3. Armor, D. J. (Ed.). (2003). Maximizing intelligence. New Brunswick, NJ: Transaction.

4. Blackburn, R. (Summer 2002). Multiple intelligences and leadership. Retrieved April 6, 2003, from ProQuest Database:

5. Bickman, L., \& Rogs, D. J. (1997). Handbook of applied social research methods. Thousand Oaks, CA: Sage.

6. Brualdi, A. C. (1996). Multiple intelligences: Gardner's theory. Retrieved December 16, 2002, from ERIC Clearinghouse on Assessment and Evaluation Washington DC Database:

7. Crainer, S., \& Dearlove, D. (1999). Death of executive talent [electronic version]. Journal of Management Review, 88 (7), 16-23 July. Retrieved July 29, 2003, from http//rdsweb2.rdsinc.com/

8. Creswell, J. W. (1994). Research design. Thousand Oaks, CA: Sage.

9. Dessler, G. (2001). Management: Leading people and organizations in the $21^{\text {st }}$ century. ( $2^{\text {nd }}$ ed.). Upper Saddle River, NJ: Prentice Hall.

10. Devlin, S., Jones P, \& Martin D. (2002). Intelligence and success: is it all in the genes? Mahwah, NJ: Lawrence Erlbaum.

11. Earley, P. C., \& Ang S. (2003). Cultural intelligence: Individual interactions across cultures. Stanford, CA: Stanford University Press.

12. Ellis, K. (2003). Making waves: with a leadership crisis on the horizon, organizations are looking within to build talent pools of their own [electronic version]. Journal of Training, 40(6), 16, June. Retrieved July 29, Retrieved July 29, 2003, from http://rdsweb2.rdsinc.com/

13. Esters, I. G., \& Ittenbach, R. F. (1999, June). Contemporary theories and assessments of intelligence: A primer. Retrieved October 20, 2003, from EBSCO Database:

14. Eysenck, H.J. (1998). A new look intelligence. New Brunswick, NJ: Transactions Publishers.

15. Fiedler, F. E. (2001). When IQ + experience = performance [electronic version].Journal of Leadership and Organizational Development, 22 (3), 132. Retrieved July 29, 2003, from http//rdsweb2.rdsinc.com/texis/rds/suite/+smeBljzCwwwFqzvh+s+svwwxFqdlprdnD

16. Fish, J. M. (2002). Race and intelligence: Separating science from myth. Mahwah, NJ: Lawrence Erlbaum Associates.

17. Freeman, L. (1999, September). When the boss is the problem . Credit Union Journal, $3(36), 18,33$ September. Retrieved July 29, 2003, from http// rdsweb2.rdsinc.com/texis/rds/suite/ + smeBljzCwwwww Fqzvh+s+svwwxFqdlprdnD

18. Gall, M. D., Gall, J. P.,\& Borg, W. R. (Eds.). (2003). Educational research: An introduction ( $7^{\text {th }}$ ed.). New York: Pearson Education Inc.

19. Gall, M. D., Gall, J. P., \& Borg, W. R. (Eds.). (1996). Educational research: An introduction (4 ${ }^{\text {th }}$ ed.). New York: Pearson Education Inc.

20. Gardner, H. (1991). The unschooled mind: How children think and how schools should teach. New York: BasicBooks.

21. Gardner, H. (1993). Multiple intelligences: The theory in practice. New York: BasicBooks.

22. Gardner, H. (1983). Frames of Mind. New York: BasicBooks.

23. Gardner, H. (1995, September 15). A cognitive view of leadership. Retrieved April 6, 2003, from EBSCO Web Site: http://web15.epnet.com/citation.asp?tb=1\&_ug=dbs+0\%2C1\%2C2\%2C3\%2C5+In+en\%2D

24. Gardner, H. (1999). Intelligence reframed. New York, NY: BasicBooks.

25. Hesselbein, F., Goldsmith, M., \& Beckhard, R. (1996). The leader of the future: New visions, strategies, and practices for the next era. ( $1^{\text {st }}$ ed.). San Francisco, CA: Jossey-Bass. 
26. Kline, P. \& Saunders, B. (1998). Ten steps to a learning organization ( $2^{\text {nd }}$ ed.). Arlington, VA: Great Ocean Publishers.

27. Lebhar-Friedman, Inc. (2003). Recruiting execs learn economics of retention at annual conference [Electronic Version]. Journal of Nation's Restaurant News, 37 (27): 18, July. Retrieved July 29, 2003 from http//rdsweb2.rdsinc.com/.

28. Locke, L.F., Silverman, S.J., \& Spirduso, W.W. (1998). Reading and understanding research. Thousand Oaks, CA: Sage.

29. Mujtaba, B. G. (2007). Workpalce Diversity Management: Challenges, Competencies and Strategies. ISBN: 1-59526-548-1. Llumina Press; website: http://www.llumina.com/store/workforcediversitymanagement.htm.

30. Mujtaba, B. (2006). Cross Cultural Change Management. ISBN: 1-59526-568-6. Llumina Press, Tamarac, Florida. Website: www.Llumina.com

31. Project Summit. (2002, December 16). Howard gardner: Multiple intelligence theory proponent. Retrieved December 16, 2002, from http://www.aenc.org/ABOUT/MI-Gardner.html.

32. Riggio, R.E., Murphy, S.E. \& Pirozzolo, F. (2002). Multiple intelligences and leadership. Mahwah, NJ: Lawrence Erlbaum Associates, Inc.

33. Robbins, S. P. (2001). Organizational Behavior (9th ed.). Upper Ruzgis, P. \& Grigorenko E.L. (1994). Cultural meaning systems, intelligence and personality. New York, NY: Cambridge University Press. Saddle River, NJ: Prentice Hall.

34. Samuda, R.J. (1998). Psychological testing of American minorities: Issues and consequences. $\left(2^{\text {nd }}\right.$ ed.). Thousand Oaks, CA. Sage Publications.

35. Shahnasarian, M. (1996). Self-Directed search in business and industry. Odesssa, FL: Psychological Assessment Resources.

36. Sternberg, R. J. (2003). Wisdom, intelligence, and creativity synthesized. New York: Cambridge University Press.

37. Sternberg, R.J., Grigorenko, E.L. (2003). The psychology of abilities, competencies, and expertise. New York: Cambridge University Press.

38. Sternberg, R.J., \& Kaufman, J.C. (2001). The evolution of intelligence. Mahwah, NJ: Lawrence Erlbaum Associates, Publishers.

39. Tyrell, B. \& Swain, B. (2000). The right stuff [electronic version]. Journal of Pharmaceutical Executive, 20 (8), 86-94. Retrieved July 29, 2003, from http://rdsweb2.rdsinc.com/texis/rds/suite/+smeBljzCwwwwwFqzvh+s+svwwxFqdlprdnD.

40. Welch, K. C. (2002). The bell curve and the politics of negrophobia. Mahwah, NJ: Lawrence Erlbaum Associates.

41. White, S. H. (2000). Conceptual Foundations of IQ Testing. Psychology, Public Policy and Law, 6(1), 33-43.

42. Wilson, S. D., (2005). The relationship between leadership and domains of multiple intelligences. UMI Microform Num: 3151206. ProQuest Information and Learning Company.

43. Yang, S. Y. \& Sternberg, R. J. (1997). Conceptions of intelligence in ancient Chinese philosophy. Journal Theories of Philosophical Psychology, 7 (2) 57-69. 